\title{
Parental psychopathology and somatic presentation in children: a comparative study
}

\begin{abstract}
Introduction: Many of the psychological problems present with pure somatic symptoms, especially among children and adolescents. The long term impact of somatisation is poor and results in compromised outcome in various areas. Children of parents having psychopathology are more prone to develop psychological problems. Thus, the present study was done to assess the relation between parental psychopathology and somatic presentation in children.
\end{abstract}

Aim and objective: To assess the parental psychopathology and its relationship with somatic presentation in children.

Research design and methods: It was a cross-sectional, case-control study design. The children of age between 9-14years who presented with psychological and emotional problems attending Paediatrics OPD from July 2013 to December 2013 were referred to Department of Psychiatry in Pt. B.D. Sharma, PGIMS, Rohtak, a tertiary care centre in northern India. Thirty children who presented with somatic symptoms constituted group-I and thirty children who presented with other psychological non somatic symptoms constituted the group-II. Their socio-demographic profile was taken on a specially designed proforma. Psychopathology among parents of both the groups was assessed by General Health Questionnaire-12 item version. The collected data was analysed statistically.

Results: It was found that depression and anxiety disorders were more common in parents of both groups. Parents of children with somatization had more psychopathology, but the difference was not statistically different between the two groups.

Conclusion: Children presenting with somatic complaints should be properly evaluated for psychological stress due to presence of psychopathology among parents.

Keywords: parental psychopathology, somatisation, parent child relation
Volume 2 Issue 2 - 2015

Priti singh,' Pratibha Gehlawat,' Balkishan Sharma, ${ }^{2}$ Virender Kumar Gehlawat, ${ }^{3}$ Rajiv Gupta $^{3}$

'Department of Psychiatry, Pt BD Sharma, PGIMS, India ${ }^{2}$ Consultant Psychiatrist, India

${ }^{3}$ Department of Pediatrics, Pt BD Sharma, PGIMS, India

Correspondence: Pratibha Gehlawat, Senior Resident, Department of Psychiatry, PGIMS, Rohtak, House no. 5/I IJ, Medical Campus, PGIMS, Rohtak, Haryana, India, Tel 967I6I5649, Email hunt4prat_0I@rediffmail.com

Received: September 07, 2014 | Published: January 20, 2015

\section{Introduction}

Somatization is associated with significant problems and disabilities in both children and adults. ${ }^{1,2}$ It accounts for a substantial proportion of hidden psychiatric disorders..$^{3-6}$ There are disproportionately large number visits to physician and out-patient clinics due to somatisation which further leads to various investigations, drug prescription and a risk of iatrogenic disease. ${ }^{7-9}$ The long term impact is poor. Children constitute a bulk of population in developing countries and merit special attention. There are various difficulties anticipated in assessment of psychiatric problems among children. They cannot recognize their psychological and emotional problems and these are more often recognized by their caretakers such as parents and teachers. Also, somatisation is found to be common in people of lesser sophistication. ${ }^{10}$ Children are less sophisticated psychologically as they have poor power of expression, less vocabulary, difficulty in understanding psychological problems. They have more tendencies to somatize as a reaction to psychological distress. Therefore, somatisation is common anxiety disorder among children and adolescents. ${ }^{11,12}$

Children of parents having psychopathology are more prone to develop psychological problems. ${ }^{13}$ Research has shown that negative life events reported by parents were associated with children's emotional and behavioural problems. ${ }^{14}$ Many of the psychological problems present with pure somatic symptoms and polysomatic presentation is found to be more common. ${ }^{15}$ This results in marked disabilities and problems like socio-emotional difficulties to children, school refusal, decline in academic performance, abnormal peer relationship and also, significant financial and psychosocial difficulties to caregivers and loss of work days in seeking medical help. The long term impact of somatisation is poor and results in compromised outcome in various areas. ${ }^{16,17}$ Previous literature suggested that somatising children were at increased risk of major depression 4years later and also more likely to describe panic attacks at 4-year followup. There was an increased risk of substance abuse and dependency in highly somatising children..$^{18}$ Therefore, it becomes important to assess the impact of having parental psychopathology on somatic presentation of children. The aim of the present study was to assess the parental psychopathology and relationship between parental psychopathology and somatic presentation in children.

\section{Material and methods}

\section{Sample}

The study was conducted in Pt B D Sharma, PGIMS, Rohtak, Haryana, a tertiary care centre in northern India over a period of six months from July 2013 to December 2013. The children and parents for the study were referred Pediatrics out-patient department of the same institute. Children between 9-14years of age and their parents attending the Pediatrics out-patient department, who had psychological and emotional problems, were referred to Department of Psychiatry. A total of 60 children and their parents (both father and mother) constituted the sample and were divided into two equal groups. 30 children and their parents who presented with somatic symptoms 
comprised the group-I. 30 children who presented with non-somatic symptoms constituted the group-II which served as control.

\section{Inclusion criteria}

i. Children of age group 9-14years and their parents irrespective of age.

ii. Children fulfilling the Diagnostic and Statistical Manual of Mental Disorder (DSM-IV) criteria psychiatric disorders.

iii. Parents who had scores above cut-off as per GHQ-12 and diagnosed as per DSM-IV.

iv. Parents who gave consent for the study.

\section{Exclusion criteria}

i. Organic brain disease

ii. Autistic spectrum disorder

iii. Mental retardation

iv. Epileps

v. Attention deficit hyperactivity disorder

vi. Psychotic disorders

vii. Any comorbid physical illness.

\section{Measures}

The socio-demographic profile was collected on a specially designed proforma which included details regarding the education status, occupation of the parents as well as the family type.

General Health Questinnaire-12 item version (GHQ-12): This questionnaire was developed by Goldberg in 1972 and aims to detect non-psychotic psychiatric illness. The original questionnaire has 140 items and later 60-, 36-, 30-, 20-, 12-, and 5-item versions were devised and tested for validity, in Indian conditions and overseas. The twelve-item version helps the general practitioner to screen quickly for psychiatric morbidity in an out-patient setting. ${ }^{19}$

Diagnostic and Statistical manual of mental disorder fourth edition (DSM-IV): The psychiatric diagnosis was made according to DSM-IV with the use of specific criteria described for specific diagnosis. $^{20}$

\section{Study design}

It was a cross-sectional, case-control study design. After explaining the method of the study, consent was taken from the parents. Children were diagnosed as per DSM-IV criteria. The parental psychopathology was assessed by GHQ-12. Those who had scores above cut-off were interviewed and diagnosed as per DSM-IV. Approval from Ethical Board of Post Graduate Institute of Medical Sciences, Rohtak, and Haryana was granted.

\section{Statistical analysis}

The data collected during the study was entered in the Microsoft excel format and was analyzed using SPSS 14 version Microsoft software. Descriptive statistical analysis was done for continuous and categorical variables. Chi Square test and unpaired student t-test was applied for comparison between the two groups. The p-values were two tailed and probability level of significant difference was set at $<0.05$.

\section{Results and discussion}

A total of sixty children in between age group 9-14years and 120 parents constituted the study sample and were evaluated. The mean age \pm S.D of parents (father and mother) between both the groups were comparable. The mean age of the children was $11.44 \pm 3.12$ years. Table 1 shows the sociodemographic profile of the two groups. It is reflected that majority of fathers were educated up to Matriculation in two groups. More fathers of children in the case group were unemployed, farmer and labourer, while in the control group more were professional, and the difference was found statistically significant. However, in both the groups' majority of the mothers were housewives and attained similar education. It also shows that group-I had significantly larger families (more than 6 members) and lower annual income as compared to group-II.

Table 2 shows DSM-IV diagnosis in children in both the groups. It shows that most of the children in group-I had conversion disorder (80\%). In group II, most children had depressive disorder followed by phobia and anxiety disorder. Table 3 shows diagnosis of parents of children in both the groups. Depressive and generalized anxiety disorder was more common in parents in both the groups. Comparison of psychopathology among father and mother on the basis of General Health Questionnaire in both the groups is shown in (Table 4). Parental psychopathology was found to be more in group-I (somatising children) than in group-II; however the result was not statistically significant. Table 5 shows the relation between parental psychopathology and somatisation in children. It was found that children had more of monosomatic presentation who had parents without psychopathology. However, in contrast, children had more of polysomatic presentation who had parents with psychopathology and the difference was statistically significant.

Table I Sociodemographic profile of the family and parents in the study group

\begin{tabular}{|c|c|c|c|c|c|c|}
\hline \multirow{2}{*}{$\begin{array}{l}\text { Variables } \\
\text { Age }\end{array}$} & \multicolumn{2}{|c|}{ Group-I $(n=30)$} & \multicolumn{2}{|c|}{ Group-II $(n=30)$} & \multicolumn{2}{|l|}{$P$ value } \\
\hline & Father & Mother & Father & Mother & Father & Mother \\
\hline$($ Mean $\pm S D)$ yrs & $38.0 \pm 6.24$ & $34.10 \pm 4.28$ & $38.40 \pm 5.34$ & $33.84 \pm 5.10$ & 0.412 & 0.405 \\
\hline \multicolumn{7}{|l|}{ Background } \\
\hline Rural & $18(60)$ & & II (36.6) & & 0.07 & \\
\hline Urban & $12(40)$ & & $19(63.4)$ & & & \\
\hline \multicolumn{7}{|l|}{ Family type } \\
\hline Nuclear & $19(63.4)$ & & $22(73.4)$ & & 0.405 & \\
\hline Joint & $11(36.4)$ & & $8(26.6)$ & & & \\
\hline \multicolumn{7}{|l|}{ Family size } \\
\hline$<6$ members & $18(60)$ & & $27(90)$ & & $0.007^{*}$ & \\
\hline$>6$ members & $12(40)$ & & $3(10)$ & & & \\
\hline
\end{tabular}


Table Continued...

\begin{tabular}{|c|c|c|c|c|c|c|}
\hline \multirow{2}{*}{$\begin{array}{l}\text { Variables } \\
\text { Age }\end{array}$} & \multicolumn{2}{|c|}{ Group-I (n=30) } & \multicolumn{2}{|c|}{ Group-II (n=30) } & \multicolumn{2}{|l|}{$P$ value } \\
\hline & Father & Mother & Father & Mother & Father & Mother \\
\hline \multicolumn{7}{|l|}{ Family income } \\
\hline$>10000$ & I (3.33) & & $0(0)$ & & & \\
\hline$>10000-20000$ & $4(13.33)$ & & I (3.33) & & & \\
\hline$>20000-30000$ & $12(40)$ & & $4(13.33)$ & & $0.0013^{*}$ & \\
\hline$>30000-40000$ & I (3.33) & & $3(10)$ & & & \\
\hline$>40000$ & $12(40)$ & & $22(73.33)$ & & & \\
\hline Education & Father & Mother & Father & Mother & Father & Mother \\
\hline Illiterate & I (3.4) & $5(16.6)$ & $0(0)$ & I (3.4) & & \\
\hline Primary & $3(10)$ & $7(23.3)$ & I (3.4) & $5(16.6)$ & & \\
\hline Middle & $5(16.6)$ & $6(20)$ & $8(26.6)$ & $8(26.6)$ & 0.161 & 0.090 \\
\hline Matric/secondary & $16(53.4)$ & $9(30)$ & $5(16.6)$ & $12(40)$ & & \\
\hline Graduation/Post grad. & $5(16.6)$ & $3(10)$ & $16(53.4)$ & $4(23.4)$ & & \\
\hline \multicolumn{7}{|l|}{ Occupation (Father) } \\
\hline Unemployed & $9(30)$ & & $8(26.6)$ & & & \\
\hline Self-employed (farmer/labourers) & $12(40)$ & & $2(6.6)$ & & & \\
\hline Skilled & & & & & $0.04 I^{*}$ & \\
\hline \multirow[t]{2}{*}{ Professional } & $7(23.4)$ & & $5(16.6)$ & & & \\
\hline & $2(6.6)$ & & $15(50)$ & & & \\
\hline \multicolumn{7}{|l|}{ Occupation (Mother) } \\
\hline Unemployed & I (3.4) & & $0(0)$ & & & \\
\hline Self-employed & $2(6.6)$ & & $0(0)$ & & 0.755 & \\
\hline Skilled & I (3.4) & & $6(20)$ & & & \\
\hline Housewife & $26(86.6)$ & & $24(80)$ & & & \\
\hline
\end{tabular}

$\mathrm{P}<0.05^{*}$ (significant)

Table 2 DSM-IV Diagnosis of the children in the study group

\begin{tabular}{lll} 
Diagnosis & Group-I n=30 (\%) & Group-II n=30 (\%) \\
\hline Conversion disorder & $24(80)$ & - \\
Undifferentiated somatoform disorder & $6(20)$ & - \\
Depression & - & $13(43.3)$ \\
Phobia & - & $7(23.3)$ \\
Panic disorder & - & $6(20)$ \\
Generalized anxiety disorder & - & $4(13.3)$ \\
Total & 30 & 30
\end{tabular}

Table 3 DSM-IV diagnosis of parents of children in study group

\begin{tabular}{lllll}
\hline Diagnosis & Group-I & \multicolumn{2}{l}{ Group-II } \\
\cline { 2 - 5 } & Father & Mother & Father & Mother \\
\hline Depression & 2 & 3 & $\mathrm{I}$ & 2 \\
Phobias & $\mathrm{I}$ & - & - & - \\
Panic disorder & $\mathrm{I}$ & $\mathrm{I}$ & - & - \\
Generalised Anxiety disorder & $\mathrm{I}$ & 2 & $\mathrm{I}$ & - \\
\hline
\end{tabular}

Table 4 Parental psychopathology on the basis of General Health Questionnaire (GHQ)

\begin{tabular}{lllllll}
\hline Psychopathology & Father & & P value & Mother & P value \\
\hline & Group-I (\%) & Group-II (\%) & 0.227 & Group-I (\%) & Group-II (\%) & \\
Present & $5(16.67)$ & $2(6.67)$ & & $6(20)$ & $2(6.67)$ & 0.128 \\
Absent & $25(83.33)$ & $28(98.33)$ & & $24(80)$ & $28(98.33)$ & \\
\hline
\end{tabular}

$P$ value $>0.05$ (not significant)

Table 5 Relation between parental psychopathology and somatisation in children

\begin{tabular}{llll}
\hline Psychopathology & $\begin{array}{l}\text { Monosomatic presentation in } \\
\text { children }\end{array}$ & $\begin{array}{l}\text { Polysomatic presentation in } \\
\text { children }\end{array}$ & P value \\
\hline Father without psychopathology $(n=25)$ & 22 & 3 \\
Father with psychopathology $(n=5)$ & I & 4 \\
Mother without psychopathology $(n=25)$ & 21 & 4 \\
Mother with psychopathology $(n=5)$ & 2 & 3 \\
\hline
\end{tabular}

$P$ value $<0.05^{*}$ (significant)

Citation: Singh P, Gehlawat P, Sharma B, et al. Parental psychopathology and somatic presentation in children: a comparative study.J Psychol Clin Psychiatry. 20I5;2(2): I I-I2. DOI: 10.15406/jpcpy.20I5.02.00059 


\section{Discussion}

Our study found that monosomatic presentation was more common in children and the most common presentation was pseudo seizure. Garber stated that $50 \%$ of children report one somatic complaint, $15 \%$ four or more and $1 \%$ may report as many as 12 symptoms. Our study supports the finding of the previous study, that majority of somatising children had monosomatic presentation. ${ }^{11}$ Dissociative disorders, mainly presenting as pseudo siezures and fainting spells, with or without co-morbid diagnosis were found to be high in clinic populations in India. ${ }^{29}$ On contrary, Mullick et al found that polysomatic presentation was commoner $(92 \%)$ than monosomatic presentation. They also found that children have significantly higher rate of abdominal pain and adolescents showed higher rate of headache. ${ }^{15}$ It was found that more parents in group-I had psychopathology (16.67\% of fathers and $20 \%$ of mothers) than group-II ( $6.67 \%$ of fathers as well as mothers). Though the difference was not significant, it supports the finding of previous studies. ${ }^{13}$ Garber et al., ${ }^{30}$ suggested that parents, especially mothers, of somatising children who had recurrent abdominal pain had more psychopathology. Also, more commonly depressive and anxiety disorders in parents was associated with somatic presentation in children and adolescents, ${ }^{31,32}$ although very limited data is available in Indian setting.

Present study is an attempt to assess the role of parental psychopathology in development of somatic symptoms in children in Indian setting. Although, it suggests that parental psychopathology is more often present in children having somatization, it has few limitations. It is a cross-sectional study and a longitudinal, interventional study may throw more light on assessment and management of children having somatic symptoms. It was a hospital based study, done in tertiary care centre. The sample size was small, so the results cannot be generalised to general population. General Health Questionnaire used in the current study only detected common mental disorder in parents, but not severe mental disorders. Assessment of parent child relationship, which may be an important factor in producing somatisation in children, should also be taken care of in further studies.

\section{Conclusion}

Current study shows that majority of somatising children had conversion disorder, while few has undifferentiated somatoform disorder. The non-somatising children mainly had depressive and anxiety disorders. Depression and anxiety disorders were common in parents of both the groups. Parents of children with somatization had more psychopathology. Therefore, it is suggested that children presenting with somatic complaints should be properly evaluated for psychological stress due to presence of psychopathology in parents.

\section{Acknowledgments}

None.

\section{Conflicts of interest}

Author declares there are no conflicts of interest.

\section{Funding}

None.

\section{References}

1. Patel V, Pereira J, Coutinho L, et al. Poverty, psychological disorder and disability in primary care attenders in Goa, India. Br J Psychiatry. 1998;172:533-536.
2. Gureje O, Simon GE, Ustun TB, et al. Somatization is cross-cultural perspective: a World Health Organization study in primary care. Am J Psychiatry. 1997;154(7):665-669.

3. Bridges RN, Goldberg DP. Somatic presentation of DSM-III psychiatric disorders in primary care. J Psychosom Res. 1985;29(6):583-587.

4. Al-Windi A. Depression in general practice. Nord $J$ Psychiatry. 2005; 141:154-158.

5. Widmer RB, Cadoret RJ. Depression in primary care: Change in pattern of patient visits and complaints during a developing depression. J Fam Pract. 1978;7:293-302.

6. Wilson DR, Widmer RB, Cadoret RJ, et al. Somatic symptoms: A major feature of depression in a family practice. J Affect Disord. 1983;5:199-207.

7. Andersen R, Francis A, Lion J, et al. Psychologically related illness and health services utilization. Med Care. 1977;15(5 SUPPL):59-73.

8. McFarland BH, Freeborn DK, Mullooly JP, et al. Utilization patterns among long term enrolees in a prepaid group practice health maintenance organization. Med Care. 1985;23:1221-1233.

9. BarskyAJ, Wyshak G, Klerman GL. Medical and psychiatric determinants of out-patient medical utilization. Med Care. 1986;24:548-563.

10. Chadda RK, Bhatia MS. A clinical study of somatising patients attending psychiatric outpatient clinic. Indian J Psychiatry. 1990;32(1):39-43.

11. Garber J, Walker LS, Semen J. Somatization symptoms in a community sample of children and adolescents: Further validation of the Children's Somatization Inventory. A Journal of Consulting and Clinical Psychology. 1991;3:588-595.

12. Garralda ME. Somatization in children. J Child Psychol Psychiatry. 1996;37(1):13-33.

13. Lloyd G. Somatization: a psychiatrist's perspective. J Psychosom Res. 1989;33(6):665-669.

14. Aggarwal S, Prabhu CH, Anand LC, et al. Stressful life events among adolescents: the development of a new measure. Indian J Psychiatry. 2007;49(2):96-102.

15. Mullick MS. Somatoform disorder in children and adolescents. Bangladesh Med Res Counc Bull. 2002;28:112-122.

16. Chandrasekaran R, Goswami U, Sivakumar V, et al. Hysterical neurosis: A follow-up study. Acta Psychiatr Scand. 1994;89(1):78-80.

17. Malhi P, Singhi P. Clinical characteristics and outcome of children and adolescents with conversion disorder. Indian Pediatr. 2002;39:747-752.

18. Zwaigenbaum L, Szatmari P, Boyle MH, et al. Highly somatising young adolescents and the risk of depression. Pediatrics. 1999;103:1203-1209.

19. Goldberg DP and Blackwell B. Psychiatry illness in general practice: A detailed study using a new method of case identification. $\mathrm{Br}$ Med J. 1970;1(5707):439-443.

20. American Psychiatric Association. Diagnostic and Statistical Mannual of Mental Disorders (4th edn), Washington DC, USA. 1994.

21. Oster J. Recurrent abdominal pain, headache and limb pains in children and adolescents. Pediatrics. 1972;50(3):429-436.

22. Sanders MR, Shepherd RW, Cleghorn G, et al. The treatment of recurrent abdominal pain in children: a controlled comparison of cognitive behavioural intervention and standard pediatric care. J Consult Clin Psychol . 1994;62(2):306-314.

23. Heillgenstein E, Jacobsen PB. iffentiating depression in medically ill children and adolescents. J Am Acad Child Adolesc Psychiatry. 1988;27:716-719.

24. Beidel DC, Christ MG, Long PJ. Somatic complaints in anxious children. J Abnormal Child Psychol. 1991;19:659-670. 
25. Walker LS, Green JW. Negative life events and symptoms resolution in pediatric abdominal pain patients. J Pediatr Psychol. 1991;16:341-360.

26. Stelnhouse HC, Aster MW, Pfeiffer E, et al. Comparative study of conversion disorders in childhood and adolescence. J Child Psychol Psychiatry. 1989;30: 615-621.

27. Walker LS, McLaughlin FJ, Green JW. Functional illness and family functioning: A comparison study of healthy and somatising adolescents. Fam Process. 1988;27:317-325.

28. Kishore J, Reddaiah VP, Kapoor V, et al. Characteristics of mental morbidity in rural primary health center of Haryana. Indian J Psychiatry. 1996;38:137-142.

29. Kearney CA, Silverman WK. Family environment of youngsters with school refusal behaviour; A synopsis with implications for assessment and treatment. Am J Fam Ther . 1995;23(1):59-72.
30. Garber J, Zemen J, Walker LS. Recurrent abdominal pain in children: Psychiatric diagnosis and parental psychopathology. J Am Acad Child Adolesc Psychiatry. 1990;29:648-656.

31. Briggs GMJ, Carter AS, Schwab SM. Discrepencies among mother, child and teacher reports: Examining the contributions of maternal depression and anxiety. J Abnorm Child Psychol. 1996;24:749-765.

32. Walker LS, Garber J, Greene JW. Somatization symptoms in paediatrics abdominal patients: Relation to chronicity of abdominal pain and parent somatisation. J Abnorm Child Psychol. 1991;19(4):379-394. 